\title{
IRIDENCLEISIS AND TRAP-DOOR IRIDECTOMY IN THE TREATMENT OF GLAUCOMA*
}

BY

\section{T. HARRISON BUTLER \\ BIRMINGHAM}

AT the first meeting of the Society that was held in Coventry, in June, 1926, I read a paper on Iridencleisis and showed some cases upon whom the operation had been performed. At that time I had performed 15 operations only, and the paper was of a preliminary character. It was published in the Trans. Ophthal. Soc. U.K., Vol. XLVI, page 353,1926 . When the paper came to me for proof correction I added a footnote stating that I had given up the operation as ineffective. I returned to trephining for a time, but one or two rather tragic results made me feel that I must give iridencleisis another trial. My determination was strengthened by a conversation with Dr. Harald G. A. Gjessing, of Drammen, Norway. He pointed out that $I$ had been too precipitate in relinquishing the operation because some of the eyes did not at once or within a limited time show the desired fall in tension, and that probably most of the cases that I had trephined after iridencleisis would have been ultimately successful without further operation. His experience was that occasionally the full effect was shown only after a month or more, and that during this period of convalescence it was necessary to employ pilocarpine, and daily massage of the globe. Subsequent experience has shown that this is true. One case strikingly exhibited the delay. Mrs. H., a private patient with a rapidly contracting field and excavation of the disc had a tension of 30 Schiötz. After iridencleisis the field showed a most unusual and rapid recovery, but the tension was still 30 . The eye was massaged for a month and pilocarpine used, and under this treatment the tension gradually fell to 20 , and to-day, 18 months later, it is still 20 , and the field is much larger than it was before the operation.

There is nothing new or experimental in the operation. It has been advocated and practised in many forms by Colonel Herbert, by Holth, Borthe, Wilmer and Gjessing, to name but a few. Wilmer (Trans. Ophthal. Soc. U.K., Vol. XLVII, p. 231) gives the statistics of 517 operations, with 87.4 per cent. of successes, and only 0.38 per cent. of late infection. Gjessing in the Arch. of Ophthal., Vol. VI, p. 489, 1931, gives a careful analysis of the follow-up examination of 122 operations with 83.5 per cent. of

* A Paper read to the Midland Ophthalmological Society on June 7, 1932, at a meeting held at the Coventry and Warwickshire Hospital, with an exhibition of cases of the operations. 
success and no late infection. In three cases only was a direct detrimental effect noted from the operation.

Before discussing the actual operation, its technique, and its results I will postulate what we desire from an operation for the relief of chronic glaucoma. It has been definitely proved that it is necessary to obtain a permeable cicatrix. The filtration should not be concentrated upon one small area, but should be diffused over a wide surface. It must be permanent, and not excessive. We desire to reduce the tension to normal, not to obtain hypotony. The procedure should not be one that causes an excessive amount of trauma, and should not in general be followed by any iritis or even ciliary injection. The cicatrix although permeable must be well covered by an adequate layer of conjunctiva so that the risk of infection of the eye is minimal. The cosmetic effect should be good, unsightly lumps and bulges must be avoided. An operation that yields a high percentage of success should be chosen only when the element of tragedy does not too frequently harrow both surgeon and patient. We are unable to cure all cases of glaucoma, but we ought to reduce the operative loss of vision and perhaps of the eye itself to very low figures.

I have been able to collect the notes of 60 iridencleisis operations. I think that I have performed about 70 in all, but owing to changes in hospital appointments, I have not been able to complete the list.

The statistics have been made in the following way : I have asked my ward sister to give me the names and numbers of the operations taken from the operation book. I then obtained the case sheets, and analysed them in the same way that I treated my trephine cases in a previous investigation. I noted the tension before operation, and that mentioned in the last note made. If the tension was normalised and the vision not made worse, the case was classed as a success. The vision was treated in the same way, acuity before operation, and final acuity recorded in the notes. The changes in the fields were noted in many cases, and the duration of the case recorded. It is obvious that these statistics are incomplete. I have not had the time or the power to re-examine all the cases: some have a short, others a long duration. But the same objection can be made to my trephine statistics which were made in exactly the same manner. The statistics favour iridencleisis, in that $\mathrm{I}$ have been performing this operation for a much shorter time, six years, whereas the trephine records were taken from 1920 to 1930, and I have many cases who were operated upon 15 and more years ago, and are still holding their own.

During the first three years that I performed iridencleisis I to some extent selected my cases, reserving the worst examples for the trephine because I had the idea that the iridencleisis was not so efficient in reducing tension as trephining, but during the past two 
years I have found that it is perfectly effective, and have practically given up trephining.

It may seem to be unfair to criticise one operation and uphold another. I wish to avoid any undue enthusiasm, and to be perfectly fair and unbiassed. Early in my operative career I was unfortunate in having an undue number of late infections, mainly after Holth's punch operation. I returned to iridectomy for chronic glaucoma. I then took up trephining and continued for several years. My experience taught me that something less dangerous was necessary, and I feel that I have found it in iridencleisis.

It seems necessary to state my views upon the advantages and dangers of trephining. These have been gained from my own operations and from conversations with colleagues, many of whom have had the same troubles as myself.

There is no doubt that trephining cures chronic glaucoma in a large number of cases if performed early enough. Wilmer (Trans. Ophthal. Soc. U.K., Vol. XLVII, p. 230) gives statistics of trephining. One surgeon with 179 operations had 72 per cent. of success. Another with $140,92.8$ per cent., and another with 3,381 had 77.6 per cent.

Wilmer himself records 88 per cent. of personal success.

In $1914 \mathrm{Mr}$. Jameson Evans and myself read a Paper to the Oxford Congress on the "Results of Modern Operations for Glaucoma" (The Ophthalmoscope, Vol. XII, p. 468). We had notes of 23 cases of trephining for chronic glaucoma and they were successful in 87 per cent. In my Middlemore Lecture for 1930 on "The Results of Ophthalmic Operations" (Brit. Jl. of Ophthal., Sept., 1931), I gathered the statistics of operations performed hetween 1920 and 1930. There were fifty trephinings for chronic glaucoma, and the percentage of success was 70 per cent. It is reasonably accurate to conclude that about 75 per cent. of all trephinings for chronic glaucoma are successful.

On the other hand it is necessary carefully to examine the cases classed as unsuccessful, and to note the number that have been definitely injured by the operation, even to the loss of the eye. We must also study the successful cases and the nature of the convalescence.

The disadvantages of the trephine operation that have led me to feel that a better operation must be sought are the following :(1) The operation is a serious insult to the eye. It is practically always followed by considerable injection, and very frequently by frank, iritis. For this reason it is the practice always to instil atropine after the operation. The patient will be an in-patient for from ten days to a fortnight.

(2) In a large proportion of the cases an ectatic bleb will form over the site of the operation, which may bulge the eyelid, and 
become a deformity. So often is this the case that one well-known ophthalmic surgeon told me that it was to him a deciding factor in rejecting the operation. Not only is this bleb unsightly, but it is a constant menace to the integrity of the eye. I have seen these ectatic scars not only in my own practice but in cases operated upon by many other surgeons.

(3) A development of myopia after the operation is common, because of the forward movement of the lens. This gradually disappears, but some of it may remain.

(4) Late formation of the anterior chamber is not rare. It is always an anxiety and may be a danger in that it leads to the development of nuclear cataract. In one case, a private patient, the anterior chamber did not reform, and a complete nuclear cataract formed. This happened in both eyes which were not operated upon at one time. The patient entered the hospital with $6 / 6$ in each eye and left blind. I was not able to extract the lens which seemed to have a consistence like glue. I have seen another case which is figured in my Guide to the Slit Lamp, p. 43. The eye had been operated upon by a colleague, and the scar was ideal. The anterior chamber remained absent for a year, and then nuclear cataract developed. Similar things have happened to others who for this reason are giving up the trephine.

(5) Post-operative cataract, developing rapidly or later on, is common. My statistics give 10 per cent., and this figure agrees with that given by other operators.

(6) Late infection resulting in the total loss of the eye has occurred in 1 per cent. of my cases. Wilmer gives the percentage as 1.2 . In addition to these serious cases there are others which are not so serious and yield to atropine and other treatment. I have two cases in mind of this kind. One private patient had several attacks, and eventually, six years after the operation, the eye was lost. She had, however, had six years of useful vision in the eye. The other was blind from glaucoma when I first saw her. In another case one attack of late infection succeeded another till I cut them short by cauterising the scar and covering it with a conjunctival flap. This operation was done with Holth's punch in 1914. She maintained useful vision till this year. Her tension is still normal, but her disc is now deeply cupped and atrophic.

(7) Occasionally a trephined eye becomes hypotonic: the evils of this condition have been pointed out by Treacher Collins (Trans. Ophthal. Soc. U.K., Vol. XXXVII, p. 281).

We may sum up by saying that trephining in chronic glaucoma gives an excellent percentage of good results, but that some of the failures are so disastrous that the operation should be given up if a 
better can be found. In my series from 1920 to 19304 per cent. were enucleated for one reason or another.

In acute glaucoma the statistics for the trephine are very bad. There are some cases in which the iridectomy has failed to achieve the desired reduction of tension and something more must be done or the surgeon decides at once that iridectomy will not suffice. In my series I had 24 such, 54 per cent. were successful, and 24 per cent. were excised. It is true that many of these were severe, neglected and complicated cases.

(8) What are the objections to iridencleisis? These are in the main purely theoretical: I have been told that in performing iridencleisis "I am deliberately doing what generations of ophthalmic surgeons have studiously tried to avoid, the inclusion of iris in a scar." "The operation is a violation of the first principles of the surgery of the eye." "Iris inclusion must lead to an irritable eye and eventually to sympathetic ophthalmitis." It is of course true that the small prolapses that occasionally follow extraction are a constant menace to the eye. Many years ago one of my patients lost her eye from this cause six years after the operation, and I know of another similar catastrophe. But the conditions after such an accidental prolapse and iridencleisis are totally different. The iris inclusion is well covered not only by conjunctiva but by Tenon's capsule. As a matter of fact these objections are proved by practice to be invalid. In none of my 70 operations has there been any suggestion of irritation from the included iris. I have had no sympathetic ophthalmitis, and as far as I am aware no case has been recorded in the literature. I do know of one case of sympathetic ophthalmitis after trephining. It was mentioned some years ago at the Oxford Congress by an American surgeon.

The only real objection to iridencleisis is that its effect is apt to be slow, and that if the after-care is not carried out conscientiously the filtration may become ineffective. In one series of trephine operations I found that 20 per cent. of the failures were due to firm healing of the hole. I cured this by using a $2 \mathrm{~mm}$. trephine instead of a $1.5 \mathrm{~mm}$., but the larger instrument introduced other complications, late formation of the anterior chamber, a larger proportion of ectatic scars, and hypotony. In any case a certain number of trephine operations fail because they are too good, the cicatrix heals normally and ceases to filter. The same is true of iridencleisis and probably of all attempts to form a permeable scar.

The advantages of iridencleisis are many:-

(1) The operation is one that does not disturb the eye. It is hardly ever followed by iritis, and rarely by any marked injection. The condition of the eye after operation is the same as after a preliminary iridectomy. It is never necessary or advisable to use 
atropine, and the patient can leave the hospital and return to work within a week.

(2) The ectatic scar is very rarely seen. In general there is a soft pad of general oedema round a dark discolouration under the conjunctiva representing the prolapsed iris. The pupil, contrary to what one might imagine, is never drawn up. In a word, the operation provides the ideal filtering scar.

(3) It is uncommon to find any change of refraction after iridencleisis, and any slight myopia is transitory.

(4) Late formation of the anterior chamber is not seen. The condition is exactly that present after an ordinary iridectomy.

(5) Post-operative cataract has not occurred in any of my cases, and it is not reported in the literature concerning the operation that I have read.

(6) I have not had a single example of even mild late infection. Wilmer (Loc. cit.) gives the percentage as 0.38 per cent.

(7) I have never seen hypotony after the operation, in fact the tendency is rather in the other direction, and, as has already been stated, massage is necessary in some cases before the tension is normalised.

(8) Quite a large number of the cases have shown an enlargement of the field of vision after iridencleisis. I have not noticed this to anything like the same extent after trephining.

Iridencleisis is as successful in acute glaucoma as in the chronic variety. It is my practice never to operate upon a congestive case till conservative measures have failed, or have been only partially successful. I have formed the impression that a case of acute glaucoma which does not yield to eserine is not generally cured by simple iridectomy. In other cases, as for example long-standing high tension, and eyes that have been treated with atropine, it is obvious from the first that something more will be necessary. For this reason, if the anterior chamber is not too shallow, I now perform iridencleisis as the operation of choice in congestive glaucoma. This operation is not more formidable than simple iridectomy and is far more effective. If the anterior chamber is very shallow I employ my method of trap-door iridectomy which I shall describe later in this paper.

I am somewhat diffident in giving my statistics of iridencleisis, for they seem too good to be true. I can only imagine that I have been very fortunate. Perhaps a real follow-up investigation would make them less flattering. 


\section{ACUTE GLAUCOMA}

$\begin{array}{lcccc}\text { Number of } & \text { operations } & \ldots & 12 \\ \text { Successful } & \ldots & \ldots & \ldots & 83.3 \text { per cent. } \\ \text { Cataract } & \ldots & \ldots & \ldots & 0.0 \text { per cent. } \\ \text { Total loss } & \ldots & \ldots & \ldots & 0.0 \text { per cent. }\end{array}$

One case developed double iritis six months later which was cured in the usual way with atropine.

\section{CHRONIC GLAUCOMA}

\begin{tabular}{lcccr} 
Number of operations &. & $\ldots$ & \multicolumn{1}{l}{44} \\
Successful & $\ldots$ & $\ldots$ & $\ldots$ & 93.2 per cent. \\
Cataract & $\ldots$ & $\ldots$ & $\ldots$ & 0.0 per cent. \\
Total loss & $\ldots$ & $\ldots$ & $\ldots$ & 0.0 per cent.
\end{tabular}

In two cases the final result was unknown. Judging by the condition recorded when the patient left the hospital both would be successful, but to be perfectly fair I have counted one as a success, the other as a failure.

\section{COMPLICATED GLAUCOMA}

(Haemorrhagic and secondary)

$\begin{array}{lcccc}\text { Number of } & \text { operations } & \ldots & 4 \\ \text { Successful } & \ldots & \ldots & \ldots & 50 \text { per cent. } \\ \text { Cataract } & \ldots & \ldots & \ldots & 0.0 \text { per cent. } \\ \text { Total loss } & \ldots & \ldots & \ldots & 0.0 \text { per cent. }\end{array}$

In one case an old interstitial keratitis recurred, but a good result was obtained after a course of N.A.B.

\section{TOTAL STATISTICS}

$\begin{array}{lllc}\text { Number of cases } & \ldots & \ldots & 60 \\ \text { Successful } \ldots . . & \ldots & \ldots & 90 \text { per cent. } \\ \text { No cataract formation, and no late infections. }\end{array}$

If these statistics be compared with those obtained in exactly the same way for trephining, the superiority of iridencleisis will be obvious. They are taken from my Middlemore Lecture (Loc. cit.)

$$
\text { ACUTE GLAUCOMA (1920-1930), }
$$

Number of operations ... $\quad \ldots \quad 26$

$\begin{array}{lllll}\text { Successful } & \ldots & \ldots & \ldots & 54 \text { per cent. }\end{array}$

$\begin{array}{lllll}\text { Cataract } & \ldots & \ldots & \ldots & 0.0 \\ \text { Total cent. }\end{array}$

Total loss, excision $\quad \ldots \quad \ldots \quad 24$ per cent. 


\section{CHRONIC GLAUCOMA}

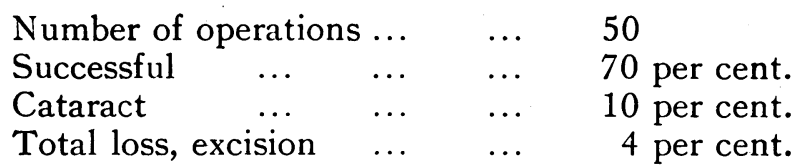

\section{Description of the Operation}

The eye is not treated with any antiseptic previous to the operation. Reliance is placed on the natural lysozyme present in the normal tears. A drop of eserine is instilled with the first application of cocaine. This is to prevent dilatation of the pupil which would make the operation difficult.

An incision is made with squint scissors horizontally about $10 \mathrm{~mm}$. above the limbus. Tenon's capsule is picked up with the forceps and the incision carried down to the sclera with a few snips of the scissors and a small pouch made.

The assistant now picks up the point of the flap, and a narrow keratome (I use my own model) is placed upon the sclera at a point about $3 \mathrm{~mm}$. from the limbus. The assistant now drops the flap over the blade of the knife which is slowly pushed into the anterior chamber till its point is seen. This is a delicate process because it is blind till the instrument appears. The keratome is now pushed in till its point is level with the centre of the cornea. It is withdrawn with a sideways movement to make the opening a rectangular rather than a triangular one. The assistant again lifts the flap and Matthieu's iris forceps is introduced to grasp the iris near the sphincter. The iris is withdrawn, and is half incised with de Wecker's scissors held backwards. This divides the sphincter. If the iris is merely withdrawn and not incised it will return into the anterior chamber. The flap is now smoothed into place and the operation is complete. No after-treatment is called for.

\section{Trap-door Iridectomy}

Ordinary iridectomy in a case of acute glaucoma is a difficult and often dangerous operation, and if performed in the classical manner, removing a large sector of the iris, it can be regarded only as a horrible mutilation. If the anterior chamber is very shallow, a not uncommon condition in congestive glaucoma, there is grave danger of wounding either the lens capsule or the back of the cornea. The first accident causes cataract, the second a permanent opacity of the cornea. It by no means follows that when a localised cataract forms after operation it is due to any lack of skill on the part of the operator. I have one case which I have followed up for several 
years. A trap-door iridectomy was performed. After the operation a localised cataract was discovered. Under the slit-lamp a wound was seen in the anterior capsule, having two horizontal lips, exactly as though a keratome had been pushed well home into the lens. I have seen this appearance twice. There is no doubt that in a case of congestive glaucoma the lens becomes turgid. When the support of the iris is removed from the capsule it may burst and produce a localised cataract. Fortunately these cataracts do not spread and are not in the line of vision. Not only is classical iridectomy dangerous, but it is apt to be followed by considerable astigmatism, and small prolapses of a dangerous type are not uncommon. I have seen them not only after my own operations, but in those operated upon by others. In the nature of things it is not always possible to avoid them. Trap-door iridectomy short-circuits all these difficulties. The operation is performed exactly as though a trephining operation was to be done with the single exception that the disc, which should always be cut with a hinge, is not removed. The trephine is inclined well forward towards the end of its work, and the disc hinges at its upper edge. The iris practically always prolapses, it is snipped off and the disc replaced like the door of the trap-door spider's lair. The surface of the sclera is smoothed down through the conjunctiva, and the flap sutured in place.

The operation has the following advantages:-

(1) There is no possibility of wounding the lens or the cornea.

(2) The iris is detached from its peripheral attachments, in such wise that the iridic angle is thoroughly freed from the root of the iris.

(3) There is no post-operative astigmatism.

(4) If there is any prolapse it is well covered by the conjunctiva and Tenon's capsule.

(5) The majority of the cases get a little permanent filtration, but an ectatic bleb is very rare.

As far as I can see there are no disadvantages. For some years I have used this operation and have given up ordinary iridectomy.

\section{STATISTICS}

I have gathered the notes of 18 operations: successful, $83 \cdot 3$ per cent.

At the Meeting a series of cases was shown both of iridencleisis and of trap-door iridectomy. 